\title{
APUNTES BIOGRÁFICOS Y BIBLIOGRÁFICOS SOBRE LA FIGURA DE D. BARTOLOMÉ JOSÉ GALLARDO (1776-1852)
}

\author{
Josefa GALLEGO LORENZO \\ Universidad de León
}

RESUMEN: Bartolomé José Gallardo fue un gran defensor de la lengua castellana y mostró especial predilección por el mundo de las letras, concretamente por la literatura y la historiografía literaria castellana y las traducciones de los clásicos barrocos, lo que amplía sus perspectivas literarias convirtiéndolo en un apasionado coleccionista y especialista de libros raros y curiosos de los siglos XV, XVI y XVII.

Fue un personaje polémico, controvertido, intelectual y defensor de los ideales liberales. Algunos autores lo definen como historiador literario, bibliógrafo y maestro de bibliógrafos. La obra que dio sentido a su largo trabajo de investigación y recopilación de datos en bibliotecas es su trabajo póstumo Ensayo de una biblioteca española de libros raros y curiosos

PALABRAS CLAVE: Bartolomé José Gallardo; Bibliografía española; Biografía.

ABSTRACT: Bartolomé José Gallardo was a great defender of the Spanish language. He showed a special predilection for the world of humanities: Castilian literature and literary historiography above all, as well as for translations of baroque classics, fact which widened his literary scope making him a passionate collector and specialist in rare and curious books from the $15^{\text {th }}, 16^{\text {th }}$ and $17^{\text {th }}$ century.

A number of authors define him as a literary historiographer, bibliographer and teacher of bibliographers. As a person, he was polemic and controversial; an intellectual and defender of liberal ideas. Ensayo de una biblioteca española de libros raros y curiosos (Essay on a Spanish Library of Rare and Curious Books), his posthumous work, gave sense to his long research and data compiling process in libraries

KEYWORDS: Bartolomé José Gallardo, Spanish bibliography.

\section{BIOGRAFÍA}

La vida de Bartolomé José Gallardo y Blanco discurrió a caballo entre los siglos XVIII y XIX. Destacó por ser un hombre de su tiempo, estudioso de amplios géneros literarios, historiador y bibliógrafo, a la vez que ocupó importantes cargos 
profesionales como catedrático de Lengua francesa en Madrid, bibliotecario de las Cortes de Cádiz y diputado por Badajoz.

Entre sus cualidades personales hay que señalar que fue un personaje polémico, controvertido, intelectual y gran defensor de la lengua castellana. Como político desarrolló un espíritu irónico y satírico que en bastantes ocasiones le acarreó numerosas críticas y fuertes polémicas por parte de sus contemporáneos. Sin embargo este polifacético personaje es una importante figura en el campo de la Bibliografía española y a pesar de ello, el reconocimiento de sus méritos ha sido muy limitado.

Simón Díaz (1995) lo define como coleccionista y buscador infatigable de libros, además de un gran conocedor de importantes bibliotecas, tanto públicas como privadas.

Nació en Campanario (Badajoz) el 13 de agosto de 1776, en el seno de una familia modesta de labradores. Su niñez transcurrió de forma tranquila hasta la edad de quince años, época en la que se trasladó a Salamanca para estudiar Teología. Son pocos los detalles que se conocen de esta primera etapa. Hoy su pueblo natal le recuerda con una placa en el lugar donde vino al mundo: "En esta casa nació el insigne polígrafo y bibliógrafo D. Bartolomé José Gallardo. N. 1776 + 1852. El Ayuntamiento de Campanario le dedica este recuerdo. 30 abril $1921^{1 " \text { ". }}$ Su nombre figura en una calle y en un Instituto de Enseñanza Secundaria, más un busto de bronce que brilla en el parque principal del pueblo. Paralelamente algunas instituciones locales y extremeñas intentan recuperar su memoria a través de diferentes actividades culturales: el Centro de Estudios Gallardianos se ocupa de la reedición y estudio de sus obras; el Ayuntamiento de Campanario patrocina el Premio Nacional de Investigación Bibliográfica "Bartolomé José Gallardo" desde 1998 y la Unión de Bibliófilos Extremeños recopila la documentación dispersa sobre Gallardo para publicar el quinto volumen del Ensayo.

Cuentan sus biógrafos que el deseo de sus padres era que fuese sacerdote y fue por ello que lo enviaron a estudiar a Salamanca. Sin embargo, una vez allí, prefirió realizar los estudios universitarios de Ciencias y Medicina aunque nunca llegó a licenciarse. Le interesó especialmente las innovaciones y avances médicos que se estaban llevando a cabo por esta época en países europeos, motivo por el cual

\footnotetext{
${ }^{1}$ José María BASANTA BARRO. "Bartolomé José Gallardo. Vida y obra". En Actas. I Jornadas bibliográficas Bartolomé J. Gallardo. [Campanario]: Centro de estudios Gallardianos: Instituto de Enseñanza Secundaria "Bartolomé José Gallardo", 1995, pp. 35-51.
} 
tradujo al castellano la obra francesa de Jean-Baptiste Pressavin ${ }^{2}$, Arte de conservar la salud y prolongar la vida, o Tratado de Higiene, editado en Salamanca por Francisco Toxar en 1800. Su inclinación por estos temas le facilitó estar en contacto con varias sociedades francesas de Medicina, completar sus estudios y formarse en este campo.

Imbuido por las corrientes innovadoras francesas le añade un prólogo a la traducción de Pressavin donde explica la importancia de esta materia y los límites que tiene esta obra. Fue tal el éxito de esta traducción que gozó de varias reimpresiones a posteriori. La importancia social del tema le llevó a traducir otros libros y a publicar varios artículos en la prensa salmantina y madrileña, en ellos se puede apreciar un estilo irónico y satírico que marcará gran parte de su obra posterior.

El conocimiento de la lengua francesa, sus viajes por Francia, así como las numerosas traducciones que realizó, le permitieron obtener un puesto por oposición de catedrático de Lengua Francesa en Madrid, convocado por el Real Colegio de Caballeros Pajes de su Majestad. A partir de 1806 se instala en Madrid lo que le favoreció para frecuentar los salones y tertulias literarias de poetas y escritores, a la par que contactaba con algunos artistas como Goya.

Durante esta etapa se intensifica su vinculación con el mundo de las letras, especialmente el de la literatura y la historiografía literaria castellana. Además se interesa por las traducciones de los clásicos barrocos lo que amplía sus perspectivas literarias convirtiéndolo en un apasionado coleccionista y especialista de los libros raros y curiosos de los siglos XVI y XVII.

Otro hecho importante que marcó profundamente su vida fue la situación política del momento: la desamortización de los bienes eclesiásticos y la guerra antinapoleónica. Estos acontecimientos influyeron tanto en su ideología como en su obra literaria hasta el punto de implicarse de forma personal combatiendo con su pluma las posturas radicales del absolutismo. Su espíritu liberal y progresista le llevó a defender la Constitución de Cádiz de 1812, lo que implicó su renuncia al puesto de profesor catedrático en la Corte para unirse a la resistencia. Destacó como articulista escribiendo en los periódicos del momento como el Semanario Patriótico o la Abeja de Madrid cuyas opiniones se caracterizaron por la firmeza y profundidad de juicio, cualidades que se hicieron patentes en muchos de sus

${ }^{2}$ L'Art de prolonger la vie et de conserver la santé, ou Traité de hygiène. Lyon : J.-S. Grabit; Paris: Cuchet, 1786, 354 p. 
escritos, lo que le valió numerosas críticas por parte de la sociedad estamental de su tiempo.

En 1811 le nombraron bibliotecario de las Cortes y su cometido fue la formación de la biblioteca, en poco tiempo gracias a sus amplios conocimientos bibliográficos acrecentó los fondos de la misma y puso a disposición de los diputados una importante colección de obras digna del estatus de la Biblioteca de las Cortes. Por estas fechas escribe el folleto Apología de los palos dados al Excmo. Sr. D. Lorenzo Calvo por el Teniente-Coronel D. Joaquín de Osma, firmado con el pseudónimo de "El licenciado Palomeque". El agudo ingenio literario desplegado en esta obra mezclado con ciertos matices políticos le proporcionaron fama de escritor célebre lo que implicó que su obra fuera reeditada numerosas veces a lo largo del mismo año.

Pero fue su Diccionario crítico-burlesco del que se titula Diccionario razonado-manual... publicado en Cádiz en enero de 1812 donde despliega su crítica más mordaz contra la sociedad y la iglesia de su tiempo, a la vez que es un alegato defensivo de la libertad de expresión y los nuevos principios políticos liberales. Esta publicación le valió un proceso y una condena por parte de la jerarquía eclesiástica.

El restablecimiento de la monarquía con la vuelta de Fernando VII trajo consigo numerosas represiones contra los liberales, provocando el exilio de Gallardo a Inglaterra donde permaneció hasta 1820. Durante su estancia en Londres frecuentó las principales bibliotecas tanto públicas como privadas, como la del British Museum o la del bibliógrafo inglés Richard Heber, que contenía una importante colección de libros raros y curiosos españoles con el objetivo de recopilar todo tipo de datos sobre la literatura española; también fueron centro de interés las librerías de anticuario en las que se dedica a buscar y comprar todo tipo de documentos impresos de temática española.

Regresa a España en 1820 durante la época del trienio liberal, siendo restituido en su cargo de bibliotecario de las Cortes, posteriormente se presenta a diputado por su provincia, Badajoz, su participación en política le acarreará de nuevo numerosas polémicas que unido a su mal carácter y aguda erudición crítica que plasma en numerosos artículos y entregas, le llevará de nuevo a ser objeto de

${ }^{3}$ Bartolomé DíAz DíAz. "Bartolomé José Gallardo, bibliógrafo, polígrafo, gramático, satírico, filósofo, lexicógrafo... y amante de la libertad. Entre Campanario y Salamanca". En Campanario. Campanario: Ayuntamiento, 2003, III, p. 84 
múltiples ataques, hecho que aumenta considerablemente la lista de sus enemigos ${ }^{4}$. Muere en Alcoy, Valencia, el 14 de septiembre de 1852.

Aunque no son muy numerosas las biografías escritas sobre Gallardo destacamos las siguientes por ser las más significativas y completas: la evocación biográfica realizada por Marqués Marchán, Don Bartolomé José Gallardo: Noticia de su vida y escrito ${ }^{5}$; la exhaustiva y documentada biobibliografía gallardiana de Sáinz Rodríguez, D. Bartolomé José Gallardo y la crítica literaria; el análisis detallado de Pérez Vidal, Bartolomé José Gallardo: Perfil literario y biográfico; el estudio documentado de Díaz y Díaz, Bartolomé José Gallardo, bibliógrafo, polígrafo, gramático... y por último la reseña biográfica de su convecino José María Basanta Barro, Bartolomé José Gallardo. Vida y obra ${ }^{6}$.

\section{SU OBRA BIBLIOGRÁFICA}

Abordar con profundidad el estudio de la obra de Gallardo no fue una tarea fácil durante muchos años debido a la carencia de inventarios y falta de estudios sobre sus papeletas y escritos; la mayor parte de su biblioteca desapareció fruto del expolio y consecuencia de los avatares políticos, pillajes y algunos destierros.

Bartolomé José Gallardo actualmente es considerado como el padre de la bibliofilia moderna gracias a su particular forma de recoger todo tipo de documentos impresos y manuscritos. Como bibliófilo le intereso la búsqueda y captura de la edición rara, a la vez que el texto desconocido, la pieza única e inédita, con el fin de enriquecer su colección y completar la bibliografía de un autor o de una materia, enumerando su contenido, extractando o copiando íntegramente los textos que él consideraba de interés. Según Sáinz Rodríguez su mérito como bibliógrafo no lo ha superado nadie en España, ${ }^{7}$ y por ello ocupa un lugar privilegiado dentro del panorama de la Bibliografía española.

Sus conocimientos teóricos en el campo de la historiografía literaria y la bibliografía debieron ser importantes a juzgar por el gran número de papeletas descritas que conservaba en su biblioteca, cuya temática iba desde la Lingüística, la Gramática, la Literatura, la Historia y el Arte hasta un detallado estudio y análisis

4 Manuel SÁNChEZ MARIANA. Bibliófilos españoles: Desde sus orígenes hasta los albores del siglo XX. Madrid: Biblioteca Nacional. Ministerio de Cultura. Ollero \& Ramos, 1993. pp. 77-79.

5. Madrid: Imprenta Perlado, 1921.

6 En Actas...., pp. 35-51.

${ }^{7}$ Alusión recogida por J. Simón Díaz. "Don Bartolomé José Gallardo, bibliógrafo”. En Actas..., p. 69. 
de los manuscritos del siglo XVI e incunables del XVI y XVII. Algunos autores señalan que Gallardo llegó a redactar unas 140.000 papeletas, cuya información estaba destinada a la publicación de varios libros que nunca llegaron a ver la luz. La mayor parte de esta documentación se perdió varias veces a lo largo de su vida, así lo describe Rodríguez-Moñino en Historia de una infamia bibliográfica, la de San Antonio de 1823. Realidad y leyenda de lo sucedido con los libros y papeles de Don Bartolomé José Gallardo: estudio bibliográfico.

Mientras fue bibliotecario de las Cortes se propuso acrecentar el fondo documental y bibliográfico, y entre sus objetivos estaba elevar su categoría para convertirla en Biblioteca Nacional de España, como así consta en los acuerdos de las sesiones de las Cortes de abril de 1811 que la denominan Biblioteca Nacional de Cortes $^{8}$. De su primera etapa como bibliotecario al frente de esta biblioteca es el Reglamento de la Biblioteca, que fue aprobado en noviembre de 1813 como "Reglamento para la planta fundamental de la Biblioteca de las Cortes y establecimiento de las bibliotecas Provinciales". Este reglamento consta de veinticuatro artículos, en los diez primeros regula el ingreso, uso y préstamo de libros, la creación de bibliotecas públicas en cada provincia, determina el fondo de colección que deben tener: libros clásicos, nacionales y extranjeros cuya temática verse sobre la provincia ${ }^{9}$, establece la publicación del catálogo bibliográfico provincial, y como medida de ingreso para aumentar el fondo establece la obligación de todo impresor y estampador de la provincia para que deposite un ejemplar de cada una de sus publicaciones a semejanza de la normas de la Biblioteca Real que ya tenía establecido por Real Orden del 15 de octubre de 1716 el precedente del Depósito Legal.

En relación a la Biblioteca de las Cortes amplía sus atribuciones quedando detalladas en últimos catorce artículos del Reglamento; entre las cuales extiende la denominación de Biblioteca de Cortes a Biblioteca Nacional de Cortes, cuya misión es la de reunir todas las obras impresas, estampadas y manuscritos de autores españoles, las obras escritas en español, sus dialectos e idiomas

8 Luis García Ejarque. "Bartolomé José Gallardo y la Biblioteca Nacional". Boletín de la Sociedad Castellonense de Cultura, julio-septiembre, 1994, LXX, pp. 317-366. Otros estudios de interés sobre el tema son: ID. "La Biblioteca Nacional de Española de Cortes y su último reglamento". En Homenaje a Justo García Morales. Miscelánea de estudios con motivo de su jubilación. Madrid: ANABAD, 1987, pp. 191-217. R. HERRERo GutiÉRrez. La biblioteca del Senado. Madrid, 1982, pp. 19-31.

9 “donde se reunirán las obras impresas y manuscritas de los autores naturales de su provincia, las impresas en ellas y las importantes, españolas y extranjeras, que tratarán de cosas de la provincia" En GARCÍA EJARQuE. "Bartolomé José Gallardo..., 1994. p. 320-321 
provinciales, los que hubieren impreso en alguno de los pueblos de la Monarquía española y, generalmente, aquellos libros más clásicos que traten de cosas de España, es decir, que la Biblioteca de las Cortes se convierta en el depósito general de las riquezas literarias de la Nación.

Se trata de unas disposiciones muy avanzadas y modernas para esta época. Sin embargo estos planes fracasaron al instaurarse de nuevo el poder absolutista de Fernando VII que derogó todas las normas y acuerdos anteriores. Años mas tarde durante el trienio liberal las Cortes de Cádiz repusieron por segunda vez a Gallardo como bibliotecario de las Cortes. Su principal objetivo era llegar a ser bibliotecario de la futura Biblioteca Nacional a la cual concurso en numerosas ocasiones. En 1838 se suprimió la Biblioteca de la Cortes.

Los primeros estudios llevados a cabo sobre su obra fueron bastante tardíos consistieron en una selección de escritos bajo el título de Obras escogidas de Bartolomé José Gallardo publicado por Pedro Sainz Rodríguez en la colección "Los clásicos olvidados" en 1928. En ella aparecen excluidas obras como el Diccionario crítico-burlesco por considerarla inferior a sus otras obras. Habrá que esperar varios años, concretamente hasta 1955, para que salga a la luz el importante ensayo bibliográfico realizado por Antonio Rodríguez-Moñino, sobre don Bartolomé J. Gallardo. Estudio bibliográfico (1776-1852), en el cual hace un estudio detallado de su obra y se dan importantes indicaciones bibliográficas para localizar los numerosos ejemplares del escritor. La crítica sostiene que esta obra es uno de los mejores análisis realizados sobre Gallardo. Esta obra fue reeditada en 1994 por la Unión de Bibliófilos Extremeños (UBEx).

La mayor parte de los especialistas coinciden en señalar que su fama y su prestigio fueron debidos a su obra póstuma Ensayo de una biblioteca española de libros raros y curiosos coordinada y aumentada por Zarco Cuevas, bibliotecario del Palacio Real y Sancho Rayón funcionario del Ministerio de Fomento que la presentaron al concurso bibliográfico de la Biblioteca Nacional de 1861 y obtuvieron el primer premio. Esta obra fue realizada a partir de las notas y papeletas descritas por Gallardo cuya intención era elaborar una historia del "ingenio español", 10 todavía inacabada y poco estudiada.

El Ensayo se considera la fuente primordial de obligada referencia en el ámbito del libro antiguo español. Es un repertorio de consulta que contiene abundante documentación sobre los libros raros y curiosos e impresos españoles de los siglos

10 J. SimÓn DíAZ. "Don Bartolomé José Gallardo, bibliógrafo”. En Actas..., p. 71 
XV, XVI y XVII. En ella podemos encontrar todo tipo de detalles, descripción de la obra, valoración de su contenido y lugar donde se encuentra el ejemplar.

Su método consistía en recoger y anotar el mayor número de datos posibles en papeletas donde condensaba sus ideas sobre los variados temas que le interesaban. Sus fichas muestran un orden cronológico y meticuloso en el que anota todas las particularidades tanto de la edición como del contenido de sus obras. Describe con rigor no sólo físicamente los ejemplares que había consultado, sino que también facilita la biografía de los autores, así como los comentarios sobre el contenido de las obras con detalladas enumeraciones sobre el estilo y la ortografía del libro; llegando en ocasiones a transcribir algunos textos, hoy desaparecidos, de los que hoy se tiene conocimiento gracias a sus fichas o papeletas. Sus fichas son el mejor ejemplo de su método bibliográfico resultado de los numerosos años de investigación. A pesar de todo el Ensayo es una muestra insignificante del cómputo total de papeletas descritas por este bibliógrafo que hoy se encuentran dispersas por diferentes centros: la Biblioteca Nacional de Madrid, la Fundación Menéndez Pelayo de Santander y colecciones privadas. Una gran parte de estas papeletas no llegaron jamás a la imprenta y ahora dos siglos más tarde, la Unión de Bibliófilos Extremeños junto con otras instituciones extremeñas se proponen recopilarlas, estudiarlas y editarlas para completar así la inmensa labor del bibliófilo y bibliógrafo de Campanario.

El Ensayo es quizás la obra más importante de la bibliografía española del siglo XIX y hoy en día es una de las fuentes más consultadas tanto por bibliógrafos como por bibliófilos e investigadores de distintas disciplinas. Fernández Sánchez ${ }^{11}$ define esta obra como el legado intelectual en el que está condensado su enorme saber y su pasión bibliográfica.

Su método creó escuela y en ella se formaron los mejores investigadores de su tiempo y de sus fuentes se nutrieron muchos bibliógrafos a posteriori, como Pérez Pastor o Valdenebro y Cisneros. Es por ello por lo que algunos autores le llaman "príncipe de la bibliografía española e ilustre polígrafo"12.

11 J. FernÁndez SÁnChez. Historia de la bibliografia en España. Madrid: El Museo Universal, 1989, p. 171.

${ }^{12}$ Cita extraída de una carta mencionada en el artículo de Bartolomé DíAz DíAz. "Bartolomé José Gallardo, bibliógrafo, ... pp. 79-128. 
Como colofón nadie mejor que Juan Manuel Rozas ${ }^{13}$ para definir el perfil de este personaje:

"Es uno de nuestros primeros medievalistas, consumado cervantista, sumo conocedor del Siglo de Oro, sobre todo de nuestra poesía y de nuestro teatro. Al mismo tiempo, es terrible polemista, escritor satírico, discreto poeta, agudo corresponsal, antólogo sensible y un fino ensayista con lenguaje propio. Y en la base de todo esto, su bibliofilia. Si hubiese sido un bibliógrafo común y corriente, sin más pretensiones que amontonar papeletas, hubiese acabado obras y obras, pero su curiosidad, su genial interés por todas las ramas que sustentan y auxilian a la literatura, le han hecho un bibliógrafo innovador, porque aporta a la cultura española de su tiempo, nada menos que una nueva metodología, una nueva forma de entender el oficio de bibliógrafo. Desde él, para ser un sobresaliente bibliógrafo hay que ser un experto filólogo".

\section{ESTUDIOS SOBRE LA VIDA Y OBRA DE BARTOLOMÉ JOSÉ GALLARDO}

A continuación recopilamos algunas de las obras más importantes realizadas sobre la vida y obra de Gallardo. Como se puede ver aunque el apartado no es muy exhaustivo sino meramente informativo no existen muchos estudios sobre la dimensión de su obra en relación a los estudios sobre su vida; estos últimos permiten trazar de forma más detallada su perfil biográfico, entre los cuales destacamos los estudios de José Marqués Marchán, Rodríguez-Moñino, Delgado Casado, Pérez Vidal. La mayor parte de las obras se localizaron en el catálogo bibliográfico Ariadna de la Biblioteca Nacional y en el catálogo colectivo de las bibliotecas universitarias (Rebiun). Otras fuentes de información importantes son los Manuales de bibliografía española y los Manuales de Historia de la literatura española a través de los cuales pudimos situar el autor.

Actas. I Jornadas bibliográficas Bartolomé J. Gallardo. [Campanario]: Centro de estudios Gallardianos; Instituto de Enseñanza Secundaria "Bartolomé José Gallardo", 1995.

Alborg, J. L. Historia de la literatura española. El Romanticismo. Madrid: Gredos, 1982, pp. 103-127.

ARtigas FerRANDO, M. D Miguel Artigas Ferrando: Una colección de cartas de Gallardo. Madrid: Victoriano Suárez, 1932. 245 p.

13 Texto recogido por J. M. BASAnta BARRO. "Bartolomé José Gallardo. Vida y obra". En Actas..., p.40. 
BARrerA, C. A. "Grandes bibliófilos españoles. D. Bartolomé José Gallardo. Noticias y recuerdos inéditos". Bibliofilia, 1951, IV, pp. 11-27.

BASANTA BARro, J. Ma. "Bartolomé José Gallardo. Vida y obra". En Actas I Jornadas Bibliográficas Bartolomé J. Gallardo. [Campanario]: Centro de Estudios Gallardianos: Instituto de Enseñanza Secundaria "Bartolomé José Gallardo", 1995, pp. 35-51.

BozAL, V. "Gallardo, Miñano y Larra en el origen de la sátira crítico-burlesca”. En Cuadernos Hispanoamericanos, 1982, 388, pp. 291-301.

Delgado CASAdo, J. Un siglo de Bibliografía en España. Los concursos bibliográficos de la Biblioteca Nacional (1857-1953). Madrid: Ollero y Ramos eds, 2001, t. 1, 414-425.

DÍAZ DÍAZ, B. "Bartolomé José Gallardo, bibliógrafo, polígrafo, gramático, satírico, filósofo, lexicógrafo ... y amante de la libertad. Entre Campanario y Salamanca". En Campanario. Campanario: Ayuntamiento, 2003, III.

DiCCIONARIO de Extremeños ilustres. Voz "Gallardo y Blanco, Bartolomé D. por Díaz Pérez, N. Madrid: Pérez y Boix, 1888, T. II, pp. 291-301.

ENSAYO de una biblioteca española de libros raros y curiosos. Formada con los apuntamientos de Don Bartolomé José Gallardo, coordinados y aumentados por D. M. R. Zarco del Valle y D. J. Sancho Rayón. Madrid. Imp. M. Rivadeneyra, 1863-1889. 4 vols. Ed. facsímil: Madrid: Gredos, 1968.

FERNÁNDEZ SÁNCHEZ, J. Historia de la bibliografía española. Madrid: El Museo Universal, 1989, pp. 160-171.

GARCÍA EJARQUE, L. La Biblioteca Nacional de Cortes y su último reglamento. En Homenaje a Justo García Morales. Miscelánea de estudios con motivo de su jubilación. Madrid: ANABAD, 1987, pp. 191-217.

GARCÍA EJARQUE, L. "Bartolomé José Gallardo y la Biblioteca Nacional”. Boletín de la Sociedad Castellonense de Cultura, julio-septiembre, 1994, LXX, pp. 317-366.

Herrero Gutiérrez, R. La Biblioteca del Senado. Madrid, 1982, pp. 19-31.

LAMA, M. A. "Don Bartolomé José Gallardo (1776-1852). Estudio bibliográfico". En Actas I Jornadas Bibliográficas Bartolomé J. Gallardo. [Campanario]: Centro de Estudios Gallardianos: Instituto de Enseñanza Secundaria "Bartolomé José Gallardo". 1995

Llanos Y Torriglia, F. Unos autógrafos de Don Bartolomé José Gallardo. Madrid : [s.n.], 1924 (Tip. de la "Rev. de Archivos, Bibliotecas y Museos"). 35 p.

MARQuÉs Merchán, J. Don Bartolomé José Gallardo: Noticia de su vida y escritos. Madrid: [s.n.], 1921 (Málaga: Tip. Zambrana). 430 p., 1 h. 
PÉREZ VIDAL, Alejandro. Bartolomé José Gallardo: sátira, pensamiento y política. Mérida: Editora Regional de Extremadura, [1999]. 400 p. (Colección Estudio; 12).

PÉREZ VIDAL, Alejandro. Bartolomé José Gallardo: perfil literario y biográfico. Mérida: Editora Regional de Extremadura, 2001. 70 p. (Cuadernos populares; $\mathrm{n}$. 60). ISBN 84-7671-611-7

REVERT CORTÉS, A. Adenda o adehala a la muerte de don Bartolomé José Gallardo en Alcoy. Alcoy: [s.n.], 1985 (Alcoy: Imp. Alcoy-Graf.). [16] p.; ISBN 84-398-5654-7.

RODRÍGUEZ-MoÑINO, A. Catálogo de los libros y papeles robados al ... bibliógrafo Don Bartolomé José Gallardo el día 13 de Junio de 1823: estudio bibliográfico. Madrid: [s.n.], 1957. $139 \mathrm{p}$.

RODRÍGUEZ-MOÑINO, A. Historia de una infamia bibliográfica, La de San Antonio de 1823: realidad y leyenda de los sucedido con los libros y papeles de Don Bartolomé José Gallardo: estudio Bibliográfico. Madrid: Castalia, [1965]. 248 p. (La Lupa y el Escalpelo; v. 4).

RoDríGUEZ-MoÑInO, A. Don Bartolomé José Gallardo (1776-1852): estudio Bibliográfico. Madrid: Sancha, 1955. 362 p. Reed, fac. Badajoz: Unión de Bibliófilos Extremeños, 1994.

ROZAS, J. M. Los periodos de la bibliografía literaria española: ejemplificados con los bibliógrafos extremeños. Cáceres: Universidad de Extremadura, 1983,

SÁINZ RODRíGUEZ, P. Estudio sobre la Historia de la crítica literaria en España: D. Bartolomé José Gallardo y la crítica literaria de su tiempo. New York: [s.n.], 1921. 387 p. Tir. aparte de la Revue. Hispanique, t. LI

SENABRE, R. Escritores de Extremadura. Badajoz: Diputación Provincial, 1988, pp. 109-126.

SIMÓN DÍAZ, J. "Don Bartolomé José Gallardo, Bibliógrafo". En Actas I Jornadas Bibliográficas Bartolomé J. Gallardo. [Campanario]: Centro de Estudios Gallardianos: Instituto de Enseñanza Secundaria "Bartolomé José Gallardo", 1995, pp. 69-75.

VelA, N. "El bibliograf, bibliotecari Bartolomé José Gallardo. 1776 Campanario (Badajoz) - 1852 Alcoi (Alacant)". Métodos de información. Enero, 1999, nº 6, vol. 28, pp. 25-30. 
